\title{
The effects of dexamethasone on oxidant/antioxidant status in kidneys of rats administered mercuric chloride
}

\author{
Turgay $\mathrm{M}^{1}$, Turgay $\mathrm{F}^{2}$, Devrim $\mathrm{E}^{3}$, Kucuksahin $\mathrm{O}^{1}$, Caydere $\mathrm{M}^{4}$, Durak $\mathrm{I}^{3}$ \\ Rheumatology Department, Ankara University Faculty of Medicine, Ankara, Turkey. devrim@ankara.edu.tr
}

\begin{abstract}
The study was aimed to evaluate the possible effects of dexamethasone on oxidant/antioxidant status in kidney tissues of rats administered mercuric chloride $\left(\mathrm{HgCl}_{2}\right)$. Thirty male Wistar-albino rats were enrolled in this study. Rats were divided into 4 groups: $G 1(n=7)$ underwent no therapy (control group), $G 2$ ( $n=8)$ received $\mathrm{HgCl}_{2}+$ physiological saline, $\mathrm{G} 3(\mathrm{n}=7)$ dexamethasone $(\mathrm{DM})+$ physiological saline and $\mathrm{G} 4(\mathrm{n}=8)$ received $\mathrm{HgCl} 2$ + DM. $\mathrm{HgCl}_{2}$ was injected subcutaneously into rats in the $\mathrm{G} 2$ and $\mathrm{G} 4$ on the first day of the study. Dexamethasone was injected intraperitoneally into rats in the G3 and G4 for 3 days. Malondialdehyde (MDA) levels, catalase (CAT), glutathione peroxidase (GSH-Px), xanthine oxidase (XO) and superoxide dismutase (SOD) activities were evaluated in the kidney tissues. Serum creatinine levels were also measured. Xanthine oxidase activity was increased in the G2 compared to the control group. Catalase activity in the control group was significantly higher compared to the other groups. In the histopathological examination of kidneys, there was a tubular degeneration in $\mathrm{G} 2$ and $\mathrm{G} 4$. It was concluded that $\mathrm{HgCl}_{2}$ administration may cause oxidative stress through increasing $\mathrm{XO}$ and decreasing CAT activities. Dexamethasone injection may partially protect the rat kidneys against oxidative reactions by preventing the increase in XO activity (Tab. 1, Ref. 33). Full Text in free PDF www.bmj.sk. Key words: oxidative stress, oxidant/antioxidant status, dexamethasone, rat kidney, mercuric chloride.
\end{abstract}

It is believed that there is a balance between oxidants and antioxidant defense mechanisms under normal conditions, and disturbance in this balance leads to oxidative stress. Reactive oxygen species (ROS) such as superoxide anion radicals $\left(\mathrm{O}_{2}^{-}\right)$are known as potent oxidants (1). The tissue levels of these products could reach very high levels during oxidative stress and antioxidant molecules have an important place in defense systems of organisms.

Free radicals can develop during normal metabolic events. Although these free radicals have potential detrimental effects to organism, it is inevitable to discontinue these metabolic events in our body (2). Antioxidant defense systems have been developed to avoid causative effects of free radicals (3). In this system, enzymes such as glutathione peroxidase (GSH-Px), superoxide dismutase (SOD), catalase (CAT), and some other molecules like ceruloplasmin and vitamin E have important roles. Xanthine oxidase (XO) is a molybdenum-containing enzyme that evolves from conversion of xanthine dehydrogenase and catalyses xanthine and molecular oxygen reaction that generates superoxide anion. Malondialde-

${ }^{1}$ Rheumatology Department, Ankara University Faculty of Medicine, Ankara, Turkey, ${ }^{2}$ Biochemistry doctorate, Ankara, Turkey, ${ }^{3}$ Medical Biochemistry Department, Ankara University Faculty of Medicine, Ankara, Turkey, and ${ }^{4}$ Ankara Teaching and Research Hospital Pathology Clinics, Ankara, Turkey

Address for correspondence: E. Devrim, Doc, Dr, Ankara Universitesi Tip Fakultesi, Tibbi Biyokimya Anabilim Dali, Dekanlik Binasi, Sihhiye, 06100 Ankara, Turkey.

Phone: $+90312595807 / 421$, Fax: +903123106370

Acknowledgements: The authors acknowledge the Ankara Hospital Pathology Clinics, Laboratory Animals Growing and Research Center. hyde (MDA) is a lipid peroxidation end product, and it can be used to evaluate lipid peroxidation, constituting oxidative stress. Free radicals and antioxidants have a balance in healthy individuals. Due to increased free radicals or decreased antioxidant levels, oxidative stress can develop and result in oxidative injury. It has been accepted that oxidative stress and oxidative injury can play an important role in inflammation, aging, atherosclerosis, hypertension, ischemic injury, carcinogenesis, mutagenesis, immunological, neurological, urological diseases, digestive system, and eyes, skin, lung, and hepatic disorders (4).

Glucocorticoids (GCs) have important roles in the treatment of several diseases due to antiinflammatory and immunosuppressive effects. It has been shown that GCs can activate antioxidant enzymes in different tissues. The effects of dexamethasone on antioxidant enzyme activity in lymphoid tissues have been studied, and it was suggested that GCs have a mechanism of action here. The effects of GCs on oxidative system are various at different tissues and organs. To our knowledge, kidneys are the target organs in predominantly inflammatory autoimmune diseases and play important roles in morbidity and mortality. The aim of this study was to evaluate the possible effects of dexamethasone on oxidant/antioxidant status in kidney tissues of rats administered mercuric chloride $\left(\mathrm{HgCl}_{2}\right)$.

\section{Materials and methods}

Thirty Male Wistar-albino rats (180-240 g body weight) were included in this study. Rats were purchased from Laboratory Animals Growing and Research Center. The study was approved by 
Tab. 1. Oxidant/antioxidant parameters in kidney tissues and serum creatinine levels in the groups (Mean \pm SD).

\begin{tabular}{|c|c|c|c|c|}
\hline & $\begin{array}{l}\text { Group-1 } \\
\text { (Control group) } \\
\end{array}$ & $\begin{array}{l}\text { Group-2 } \\
\left(\mathrm{HgCl}_{2} \text { group) }\right.\end{array}$ & $\begin{array}{l}\text { Group-3 } \\
\text { (DM group) }\end{array}$ & $\begin{array}{l}\text { Group }-4 \\
\left(\mathrm{HgCl}_{2}+\mathrm{DM}_{\text {group}}\right)\end{array}$ \\
\hline \multicolumn{5}{|l|}{ Kidney } \\
\hline MDA (nmol/mg) & $0.757 \pm 0.112$ & $0.696 \pm 0.096$ & $0.522 \pm 0.153$ & $0.728 \pm 0.407$ \\
\hline $\mathrm{XO}(\mathrm{mIU} / \mathrm{mg})$ & $0.137 \pm 0.013$ & $0.177 \pm 0.011 * \#$ & $0.199 \pm 0.075$ & $0.132 \pm 0.032 \#$ \\
\hline $\mathrm{SOD}(\mathrm{U} / \mathrm{mg})$ & $58.34 \pm 2.23$ & $54.37 \pm 3.80$ & $56.94 \pm 14.39$ & $50.52 \pm 5.66$ \\
\hline GSH-Px (IU/mg) & $0.053 \pm 0.006$ & $0.055 \pm 0.013$ & $0.043 \pm 0.016$ & $0.040 \pm 0.011$ \\
\hline CAT (IU/mg) & $84.29 \pm 10.79$ & $54.63 \pm 10.91 *$ & $37.15 \pm 11.30 *$ & $44.93 \pm 15.52 *$ \\
\hline \multicolumn{5}{|l|}{ Serum } \\
\hline Creatinine (mg/dL) & $0.39 \pm 0.03$ & $2.41 \pm 1.72 *$ & $0.46 \pm 0.07$ & $2.48 \pm 1.70 * \#$ \\
\hline
\end{tabular}

the Ethics Committee of Ankara University Veterinary Faculty (Decision date, and number: 30 October 2003, 2003/31). They were divided into the 4 groups. The Group G1 $(n=7)$ underwent no therapy (control group), G2 ( $\mathrm{n}=8)$ mercuric chloride + physiological saline, G3 $(n=7)$ dexamethasone + physiological saline and G4 $(\mathrm{n}=8)$ mercuric chloride + dexamethasone administrations. Mercuric chloride was injected subcutaneously (s.c.) at the dose of $1.5 \mathrm{mg} / \mathrm{kg} /$ body weight into the G2 and G4 rats on the first day of study. Dexamethasone (DM) at a dose of $1 \mathrm{mg} / \mathrm{kg} /$ body weight was injected intraperitoneally into the G3 rats and G4 rats for 3 days. Rats were sacrificed on the fourth day after the injection. Thoracic cavities of rats were opened. Blood samples were obtained from right ventricles of the animals for the determination of serum creatinine levels. Serum creatinine levels were measured to evaluate kidney functions and renal damage. Kidneys, removed from the rats, were fixed in $10 \%$ formalin and kept in aluminium foil for ten days at $-30{ }^{\circ} \mathrm{C}$ before examined. Kidney sections were transported to Ankara Hospital Pathology Clinics and stained with hematoxylin-eosin. Sections were prepared for conventional histopathologic examination; enzymatic activities were measured in kidney homogenates.

\section{Biochemical analysis}

The levels of malondialdehyde (MDA), and the activities of antioxidant (SOD, GSH-Px and CAT), and oxidant (xanthine oxidase (XO)) enzymes were measured in kidney tissue. The tissues were homogenized in the physiological saline ( $1 \mathrm{~g}$ in $5 \mathrm{ml})$ using a homogenizer (B. Braun MelsungenAG 853202, Germany) and then, centrifuged at $5000 \mathrm{x}$ g for $20 \mathrm{~min}$ (Heraus Labofur 200, Germany). Clear supernatants were removed to be used in analyses. Protein levels were measured by using the Lowry's method (5). MDA levels were determined by the thiobarbituric acid reactive substances method (6), and XO activity was determined by measuring the uric acid formation from xanthine substrate at 293 $\mathrm{nm}$ (7). GSH-Px activity was measured by subsequent changes in NADPH absorbance at $340 \mathrm{~nm}$ (8), and CAT activity by measuring a decrease of $\mathrm{H}_{2} \mathrm{O}_{2}$ absorbance at $240 \mathrm{~nm}$ (9). For the activity calculation (IU-international unit), extinction coefficients of uric acid, $\mathrm{H}_{2} \mathrm{O}_{2}$ and NADPH were used for XO, CAT and GSH-Px, respectively. SOD activity was measured by the method based on nitroblue tetrazolium (NBT) reduction rate. One unit for SOD activity was expressed as the enzyme protein amount causing 50 per cent inhibition in NBT reduction rate (10). Serum creatinine levels were measured by the method based on the color reaction between alkaline picrate and creatinine (11). All spectrophotometric measurements were made by the UV-visible spectrophotometer (Unicam He $\lambda$ ios alpha, England).

\section{Statistical analysis}

Data were evaluated by the SPSS for Windows (version 11, SPSS Inc, Chicago USA). One way variance analysis (ANOVA) and post-hoc Tukey HSD test were used to determine differences between the groups. The result was considered significant if the p-value was lower than 0.05 .

\section{Results}

The results are given in the Table 1 . Xanthine oxidase activity was increased in the G2 group compared to the control group. On the other hand, there was no difference in the xanthine oxidase activities between the control and G4 groups. The catalase activity in the control group was significantly higher compared to the other groups.

Normal tubular lumen, no tubular epithelial degeneration, normal glomerulus and diameter were observed on histopathologic examination of the G1 rats (control group). In the G2 group, there were tubular epithelial degeneration, dense eosinophilic appearance, accumulation of eosinophilic material on tubular lumen. Minimal hydropic degeneration on tubular epithelial, minimal eosinophilic material on lumen were showed in the G3 group. Minimal glomerulus edema, increasing glomerulus diameter, tubular epithelial degeneration, and eosinophilic material on lumen were evaluated in the G4 group. Especially, in histopathological examination of kidneys, there was a tubular degeneration in the $\mathrm{G} 2$ and $\mathrm{G} 4$ study groups, which received $\mathrm{HgCl}_{2}$.

\section{Discussion}

Oxidative stress may be the cause of changes in protein and nucleic acid structures, and elevation of intracellular calcium levels, injury of membrane permeability and lipid peroxidation. In these effects, lipid peroxidation is an important reason for several pathological conditions.

In our body, there are two defense mechanisms related to free oxygen radicals. First, enzymatic system consists of mainly CAT, SOD, and GSH-Px. Second, non-enzymatic antioxidant system 
consists of vitamin $\mathrm{C}$, vitamin $\mathrm{E}$, and uric acid, etc. If the balance between antioxidant system and ROS is destroyed, tissue injury can develop (12).

Oxidative stress associated with ROS has been suggested to be involved in the pathophysiology of aging and various age-related diseases, including cataracts, atherosclerosis, neoplastic diseases, diabetes, diabetic retinopathy, chronic inflammatory diseases of the gastrointestinal tract, aging of skin, diseases associated with cartilage, Alzheimer's disease, and other neurological disorders (13). SOD, primary enzymatic defense system, resides in cytosole $(\mathrm{Cu} / \mathrm{Zn})$ and in mitochondria $(\mathrm{Mn})$, and catalyses dismutation of superoxide radicals to hydrogen peroxide and oxygen, and so protects aerobic organism against the potential damage of superoxide radicals (14). GSH-Px is a metalloenzyme that consists of selenium and resides in cell membrane, decomposes $\mathrm{H}_{2} \mathrm{O}_{2}$ to water by converting reduced glutathione to oxidized glutathione. CAT converts $\mathrm{H}_{2} \mathrm{O}_{2}$ to water and molecular oxygen.

ROS have been implicated in the pathogenesis of various models of glomerular disease (15). Xanthine oxidase is a molybdenum-containing enzyme that evolves from conversion of xanthine dehydrogenase, the prevailing form of the enzyme in physiologic conditions (16). Compared to other organs, the activity of antioxidative enzymes in kidney is rather high $(17,18)$ However, this high activity is mostly confined to the renal tubules, whereas the glomerulus is not so well equipped with antioxidative enzymes (19). Azhar et al suggested that there is a weak antioxidant system in rat kidneys (20). In animals, oxidative stress could be experimentally developed with ischemia-reperfusion model and administration of heavy metals $(21,22)$. Mercuric may reduce free sulphidril groups in renal tubules. This effect can cause oxidative stress. Also, mercuric chloride may lead to acute tubular necrosis. Mercuric can accumulate in kidneys, and in comparison to ischemia-reperfusion model, develops little systemic stress. So, in our study, mercuric chloride was used to create oxidative stress in rat kidney. Histopathological examination was made to show tubular degeneration in rat kidney due to mercuric chloride.

There was a statistically significant increase of serum creatinine levels in G2 and G4 rats compared to the control group from blood samples on the fourth day of the study. Also, in the histopathological examination of kidney tissues, tubular epithelial degeneration, dense eosinophilic prospects, and accumulation of eosinophilic material, cellular debris on lumen, tubular epithelial necrosis were detected especially in the G2 and G4 groups. According to these findings, mercuric chloride has potent toxic effects on kidneys and can impair renal functions.

GCs have been used in the treatment of several diseases due to their anti-inflammatory and immunosuppressive effects. The effects of migratory cells and cytokines lead to oxidative stress, and can activate antioxidant system during inflammation. It is believed that GCs have an important role in immune system in case of stress due to oxidative stress (23). This study was aimed to evaluate the effects of GCs on this system by achieving oxidative stress in kidney tissue.

It is possible that a single dose injection of $\operatorname{IgG}$ or heterolog anti-serum to isolated tubular structures from rat kidney can form glomerular disease model in the kidney. In this model, the increased ROS formation is responsible for proteinuria (24). On the membraneous nephropathy model, the role of $\mathrm{XO}$ on proteinuria physiopathogenesis had been studied (16). As we know, XO catalyses xanthine and molecular oxygen reaction and produces superoxide anion. It was showed that CAT, SOD, and GSH-Px activities are reduced in rats with mesangioproliferative glomerulonephritis (25). Another study suggested that XO had an important role in renal disorders due to kidney reperfusion injury model (26). In our study, there were statistically significant differences between the G1-G2, G1-G3, and the G3-G4 groups regarding XO levels. This meaningful finding was manifested in rats with $\mathrm{HgCl}_{2}$ administered. However, MDA levels were not increased after $\mathrm{HgCl}_{2}$ administration. Differences between oxidative stress models may cause damages in different parts of kidney tissue. The results of our study demonstrated that mercuric chloride injected rats had tubular injury in their kidneys on histopathological examination. We also showed that the increased ROS levels were associated with decreased antioxidant enzyme activities, thus revealing a profound impairment in the oxidant-antioxidative balance in this model of kidney injury with $\mathrm{HgCl}_{2}$ administration.

In the study, it was observed that SOD, CAT activities decreased significantly, but GSH-Px activities increased in rats with injected carbon tetrachloride at the end of 72 hour (27). Another study showed that antioxidant enzyme activities had not significant differences in rats with renal injury due to adriamycine administration (28). Glucocorticoids administered in pregnancy accelerated production of kidney antioxidant enzymes, and induced antioxidant enzymes in fetal rat lungs (29). Stress or GCs increased glutathione level in male rat kidneys (30). Methylprednisolone protected glomeruli from oxidant injury by increasing antioxidant enzyme activities (31). Stacchiotti et al. proposed that bimoclomol, a stress proteins coinducer, lessened $\mathrm{HgCl}_{2}$ nephrotoxicity in rats by early recruitment of stress proteins in midcortical proximal tubules. They concluded that bimoclomol might represent a different strategy for the treatment of metal nephrotoxicity in humans (32). In the study, effects of DM on small bowel and kidney oxidative stress in bile duct ligated rats were evaluated and it was found that DM reduced oxidative stress both in small bowel and kidney via increasing SOD, CAT and GSH-Px enzyme activities and decreasing MDA levels (33).

In our study, there was no a statistically significant difference for other antioxidant enzyme except CAT. There were statistically significant differences in CAT activities between the G1-G2, G1G3, and the G1-G4. According to this finding, compared to the control group, CAT activities of other groups (G2, G3, and G4) were lower. This may explain that glucocorticoids have local effects on oxidant/antioxidant system in kidney tissue. Several results associated with kidney antioxidant enzyme activities were described in literature. These results can be obtained due to kidney model differences, oxidative stress status, levels of glucocorticoid receptors in tissues.

In conclusion, $\mathrm{HgCl}_{2}$ administration may cause oxidative stress through increasing the xanthine oxidase and decreasing catalase activities in rat kidney tissues. Dexamethasone injection may 
partially protect the rat kidneys against oxidative reactions by preventing the increase in the xanthine oxidase activity.

\section{References}

1. Soma VR, Cavusoglu E, Vidhun R, Frishman WH, Sharma SK. Contrast-associated nephropathy. Heart Dis 2002; 4 (6): 372-379.

2. Freeman BA, Crapo JD. Biology of disease: free radicals and tissue injury. Lab Invest 1982; 47 (5): 412-426.

3. Niki E. Antioxidants in relation to lipid peroxidation. Chem Phys Lipids 1987; 44 (2-4): 227-253.

4. Cross CE, Halliwell B, Borish ET, Pryor WA, Ames BN, Saul RL et al. Oxygen radicals and human disease. Ann Intern Med 1987; 107 (4): 526-545.

5. Lowry OH, Rosebrough NJ, Farr AL, Randall RJ. Protein measurement with the Folin phenol reagent. J Biol Chem 1951; 193 (1): 265-275.

6. Dahle LK, Hill EG, Holman RT. The thiobarbituric acid reaction and the autoxidations of polyunsaturated fatty acid methyl esters. Arch Biochem Biophys 1962; 98: 253-261.

7. Hashimoto S. A new spectrophotometric assay method of xanthine oxidase in crude tissue homogenate. Anal Biochem 1974; 62 (2): 426-435.

8. Paglia DE, Valentine WN. Studies on the quantitative and qualitative characterization of erythrocyte glutathione peroxidase. J Lab Clin Med 1967; 70 (1): 158-169.

9. H A. Catalase. In: HU B, editor. Methods of enzymatic analysis. New York: Academic Press Inc.; 1974. p. 673-677.

10. Durak I, Canbolat O, Kavutcu M, Ozturk HS, Yurtarslani Z. Activities of total, cytoplasmic, and mitochondrial superoxide dismutase enzymes in sera and pleural fluids from patients with lung cancer. J Clin Lab Anal 1996; 10 (1): 17-20.

11. Vasiliades J. Reaction of alkaline sodium picrate with creatinine: I. Kinetics and mechanism of formation of the mono-creatinine picric acid complex. Clin Chem 1976; 22 (10): 1664-1671.

12. Shah AM, Channon KM. Free radicals and redox signalling in cardiovascular disease. Heart 2004; 90 (5): 486-487.

13. Stohs SJ. The role of free radicals in toxicity and disease. J Basic Clin Physiol Pharmacol 1995; 6 (3-4): 205-228.

14. Yamaguchi S, Sakurada S, Nagumo M. Role of intracellular SOD in protecting human leukemic and cancer cells against superoxide and radiation. Free Radic Biol Med 1994; 17 (5): 389-395.

15. Shah SV. The role of reactive oxygen metabolites in glomerular disease. Annu Rev Physiol 1995; 57: 245-262.

16. Gwinner W, Plasger J, Brandes RP, Kubat B, Schulze M, Regele $\mathbf{H}$ et al. Role of xanthine oxidase in passive Heymann nephritis in rats. $\mathrm{J}$ Am Soc Nephrol 1999; 10 (3): 538-544.

17. Lenzen S, Drinkgern J, Tiedge M. Low antioxidant enzyme gene expression in pancreatic islets compared with various other mouse tissues. Free Radic Biol Med 1996; 20 (3): 463-466.
18. Marklund SL. Extracellular superoxide dismutase and other superoxide dismutase isoenzymes in tissues from nine mammalian species. Biochem J 1984; 222 (3): 649-655.

19. Gwinner W, Deters-Evers U, Brandes RP, Kubat B, Koch KM, Pape $\mathbf{M}$ et al. Antioxidant-oxidant balance in the glomerulus and proximal tubule of the rat kidney. J Physiol 1998; 509 (Pt 2): 599-606.

20. Azhar S, Cao L, Reaven E. Alteration of the adrenal antioxidant defense system during aging in rats. J Clin Invest 1995; 96 (3): 1414-1424.

21. Paller MS. Renal work, glutathione and susceptibility to free radicalmediated postischemic injury. Kidney Int 1988; 33 (4): 843-849.

22. Stohs SJ, Bagchi D. Oxidative mechanisms in the toxicity of metal ions. Free Radic Biol Med 1995; 18 (2): 321-336.

23. Hassan NF, Douglas SD. Stress-related neuroimmunomodulation of monocyte-macrophage functions in HIV-1 infection. Clin Immunol Immunopathol 1990; 54 (2): 220-227.

24. Shah SV. Evidence suggesting a role for hydroxyl radical in passive Heymann nephritis in rats. Am J Physiol 1988; 254 (3 Pt 2): F337-344.

25. Gaertner SA, Janssen U, Ostendorf T, Koch KM, Floege J, Gwinner W. Glomerular oxidative and antioxidative systems in experimental mesangioproliferative glomerulonephritis. J Am Soc Nephrol 2002; 13 (12): 2930-2937.

26. Greene EL, Paller MS. Oxygen free radicals in acute renal failure. Miner Electrolyte Metab 1991; 17 (2): 124-132.

27. Szymonik-Lesiuk S, Stryjecka-Zimmer M, Slomka M, Maldro A, Celinski K, Wielosz M. Catalase, superoxide dismutase, and glutathione peroxidase activities in various rat tissues after carbon tetrachloride intoxication Journal of Hepato-Biliary-Pancreatic Surgery 2003; 10 (4): 309-315.

28. Julicher RH, Sterrenberg L, Haenen GR, Bast A, Noordhoek J. The effect of chronic adriamycin treatment on heart kidney and liver tissue of male and female rat. Arch Toxicol 1988; 61 (4): 275-281.

29. Asayama K, Hayashibe H, Dobashi K, Uchida N, Kato K. Effect of dexamethasone on antioxidant enzymes in fetal rat lungs and kidneys. Biol Neonate 1992; 62 (2-3): 136-144.

30. Ogasawara M, Nomura K, Shibata N, Ujihara M, Kobayashi M, Demura H. Surgical stress increases renal glutathione content via increased glucocorticoid, and resistance to subsequent oxidative injury in the rat: significant link between endocrine response and cell defense system under the stress. Endocr J 1999; 46 (1): 99-106.

31. Kawamura T, Yoshioka T, Bills T, Fogo A, Ichikawa I. Glucocorticoid activates glomerular antioxidant enzymes and protects glomeruli from oxidant injuries. Kidney Int 1991; 40 (2): 291-301.

32. Stacchiotti A, Borsani E, Ricci F, Lavazza A, Rezzani R, Bianchi R et al. Bimoclomol ameliorates mercuric chloride nephrotoxicity through recruitment of stress proteins. Toxicol Lett 2006; 166 (2): 168-177.

33. Ozturk H, Eken H, Buyukbayram H. Effects of dexamethasone on small bowel and kidney oxidative stress and histological alterations in bile duct-ligated rats. Pediatr Surg Int 2006; 22 (9): 709-718.

Received February 18, 2011. Accepted September 20, 2011. 